\title{
Paruman The Khemion Master: Learning Chemistry Periodic table with Trading Card game
}

\begin{tabular}{ccc}
\hline Satrya Mahardhika & Frans Santoso & Nashiruddin Alfath \\
Visual Communication Design & Visual Communication Design & Visual Communication Design \\
School of Design & School of Design & School of Design \\
Bina Nusantara University & Bina Nusantara University & Bina Nusantara University \\
Jakarta, Indonesia & Jakarta, Indonesia & Jaka, Indonesia \\
smahardhika@binus.edu & frans@binus.edu & praytodream@gmail.com \\
\hline
\end{tabular}

\begin{abstract}
The purpose of this research is to learn about how IP character can help students remembering their lesson. In this case we apply the research to a subject that majority students having difficulty to learn, it is chemistry. Some students say that chemistry is the hardest subject for them. Some say that the hardest part is to remember codes and elements on chemistry. Even they said it is the most boring subject, and usually they get a bad mark for it. Based on our survey, we find out that most of students having difficulties to study the subject using traditional method. They prefer to learn using graphics, because it is easier to remember the codes. For this case, we create a set of play card that can help students remembering the chemicals codes. Each card has a unique IP Character that resembles chemical element. Writers also add an element, which could make the chemistry lesson easier to understand, that is game. A game rule will be applied on the card game, and it will help student learned chemistry. And to make it more attractive and fun, we also try to put some technology to the game. Using a technology called Augment Reality, we try to engage students more.
\end{abstract}

Keywords—ip character; learning process; chemistry; game

\section{INTRODUCTION}

Chemistry lesson is one of the toughest subject for students. Almost all students are having dificulty to remember all the codes of chemistry. We indicates that into a problem, and this time we come up an idea how IP Characters and a common and typical problem that every students will meet. Students usually learn the elements using table called Periodic Table. The table contains so many elements and students must memorized them all, it simply a hard thing to do. During this observation, we produce a set IP Character to represent elements of chemical. Using that game, student will try to remember the elements of chemical using a fun way, using something that they are mostly loving it, that is playing games. Writers also conducting a reserach about how a card gameplay could help explaning the idea of a chemistry. Writers also producing an animated trailer of the card game. During this research, writers have conducted an interview with Ramadhan Dwiputra, CEO of Pawitra Studio. He has learn and IP practitioner for more than 6 years. Writers also conducting a survey for 100 middle school students at Jakarta to get accurate information about students that having dificulty with chemistry lessons. And the result are quite surprising as $75 \%$ of the corespondence student agree that chemistry is a hard to understand. The next fact is $84 \%$ of student is having a low grade for chemistry subject. And around $80 \%$ student admit there are having dificulty to remember codes and elements of the chemistry. The next question is about using picture to memorized, 53\% student agree that picture could help them.

According Kamilati [1] in his book "IPA Terpadu" explaining about there are 118 natural chemical element and synthetic elements. Robert Boyle is the first scientist who applies names and codes for the elements. According Windura [2] memory is recoding proses of some information. Memorizing is the brain most important activity of all the time. Because we need to memorize things to learn something new. The recall of the past information in our brain is called rehearsal, and it has two functions: to maintain information in short term memory and to transfer information from the short term to long term memory. The other method is coding, which is pretty efficient to memorize something. Lesmana [3] said that there are many ways to memorized things: calm, imagine, listen and feel it, think out of the box, using emotion, take action, exaggerate, using color and repeat the information. Willis ${ }^{(4)}$ explain that double simulation could lead to a better result of memorizing. The more brain holding information, the more interconnection that could happen. It could also help student to get more information with their sense, so student can visualize the chemical elements.

\section{METHOD}

First, authors conducted several observations, from reading articles through meet with some people who expertise in this field. The method itself by observing the field which relative to the game field. Conversation and further discussion also conducted to grab more information. Mr. Ramdhan Dwiputra, CEO Pawitra Studio, Pawitra Studio previously known as Kampung Monster Studio. According to him, market validation or market studies are a must to recognize whether the story will be accepted or not, thus we can continue to develop the contents into several other contents. Moreover, he also stated any contents produced supposed to be good and 
user looking for it. Since they like it then they become loyal fans, from this point we can continue developing the other products to keep the fans updated and gain more fans. With this strategy we can offer the products to attract investor so in the future it can be developed with more budget and gain profit. Second, we observe a lot of games that succeed with its character and have several stream in other media as well. Mostly they have all the social media stream as well as the TV series to promote its character. Also other products like trading cards, action figures, and other merchandise continue the business to the next level. We can found it in games like Pokemon, Yugi-Oh, and Yo-Kai Watch.

\section{LITERATURE REVIEW}

\section{A. Visual Communication Theory}

Good graphic designer can produce a set of visual assets that is easy to use and easy to remember to the audience. We find out that application of Gestalt theory is the most accurate for this research. Graphic designer attends to learn human tendencies during an examination of some visual aid. This fact is suitable to the Gestalt theory, which examine something into one whole unity. Intellectual Property or IP is a result of creativity that can be owned by a person or entity. In this case, IP is connected to a Canvas Model Business. According to Osterwalder \& Pigneur [5] CS (Customer Segment) is the first element that shows which segment can be the main target. VP (Value Proposition) is the benefit for the customer. $\mathrm{CH}$ (Channels) using the right channel, we can communicate Value Propositions to the customer segments. CR (Customer Relationships) is how we maintain connection to the customer. $\mathrm{RS}$ (Revenue Stream) is the income. KR (Key Resource) is the primary resource to do the whole business model. KA (Key Activities) is the kind of activities to create value prepositions. KP (Key Partnership) is outsourcing activities that we use to support the business model.

From Osterwalder \& Pigneur [5] book we also find that there are Pattern Business. The patterns are: Long tail, is a pattern that selling a lot of product with small market and small sales. Unbundled is a strategy of that has three main fundamentals which is Customer Relation Business, Product Innovation Business and Infrastructure Business. The next pattern is Multi-sided Platform, which is a joint venture between two independent groups. The fusion will create a new value proposition with the connection among all different groups. The next pattern is Open, which is to create a new product that can be used as a collaborative product. And the last pattern called Free, and there are two rules: Freemium, is a free product with some more feature if the user pays more, and the other one is Bait and Hook which offering a free service at the beginning for trial and will be charged after the trial is ended.

\section{B. Game Theory}

Game is an interactive media that people usually do to satisfy themselves in the virtual world. There are four elements that a game should have: Mechanism is a group of procedure or rules that a game should have. Story is the second element that is a must in the game. The next will be Esthetics that could become a unique identity for the game. The last will be technology that could engage player to dive to the world of the game. In this case we will take deeper look on the Trading Card Games, which is quite famous around the globe. The game has been changed from every aspects and it has been progressing starting from the card design, to the way how people play. Trading Card Game also has a broad target audience market, ranging from children to adults. Each Trading Card Game has its own set of rules and regulations, either from the rules of play, stage play, right down to the types of cards. Augmented reality is a technology that adds / combines virtual objects generated by computers with the real world. Augmented reality is interactive. Augmeneted reality technology requires four main components: - Input, tools for the input can be a marker, such as this study the authors make the card as a marker that can be viewed in 3D character. Output / Display Output / display may be a head mounted display is a tool placed above the head can also be handled like mobile phone, tablet PC, or other mobile devices. Tracking Tracking tool can be either a camera or other potik sensor, GPS, wireless sensors etc. - The computer or processor Is the end result that can be read from a data programming will be a $3 \mathrm{D}$ character in the input card game. Research on AR technology can be divided into five categories, popular, first is the field of advertising and marketing: the second is the third field of entertainment education.

\section{IP Character Theory}

IP Character could be divided into three parts ; 1 . Realistic, similar to the original condition in the real world. It is meant to convey the information as detailed and as closely as possible to what exists in real life. Iconic, is a format of an iconic character, generally the designer intends to communicate same information with realistic but reduce a lot of detail. Abstract, shapes, lines, and colors are used as a symbol.

\section{Color Theory}

During the design prosess, there are a lot of elements that is very important, one of the example is color. A color is a process that occurs where the light hits an object. Everyone love color because it is able to provide beauty and aesthetic value. Color is also considered to have an influence on a person's psychology. There are various theories, one of the example is the Munsell color thory. In the making of the IP characters, writers used color that is dominated by primary colors and analogus due to cultural influences Indonesia has only two seasons, summer and rain, have caused the child's experience Indonesia who are accustomed to seeing a color that is warm and cool. It is quite different from the west that has four seasons and the experience of seeing a wide variety of colors. Therefore, the colors are often used in references such as Pokemon and Digimon so the audience especially children in order to stimulate their imagination. 


\section{DISCUSSION}

\section{A. The beauty of a Card Game}

Card game is a method of game that very famous recently, it conducts several players into a situation that they have to combine every card they have or trade with other players. So many things are very interesting in this card game, from the stories, how to play, and the design itself. One of the most famous development from card game is a Trading Card Game or Collectible Card Game. It is a game that use particular set of cards and combined with a strategic gameplay. It has very wide-ranging of target markets from children until adult. It also has different gameplay, unique design with amazing illustrations. Thus, Trading Card Game has a lot of fans and players who intend to collect rare cards and want to play and challenge other players with unique strategies that always can be changed according to the situation. Every Trading Card Games have their own rules, from how to play, level or step to reach higher state, and different type of cards.

A sample that succeed in the game field is Yugi-Oh!, It started from a manga comic in Japan. The comic itself has a lot of fans that like it story and experience told by the author. Moreover, in Japan a succeeded comic always has an animated version. The animation brings the Yugi-Oh! to the next level, it is described how the character moves, how to use the cards, how to fight between human and monster and the important thing is it indicated us how the story brought further into fantasy atmosphere and amazing imaginations. From this point the Yugi-Oh! gain more fans that enjoy all the entertainment and they give feedback to the creator. In addition, the creator work with another team to bring Yugi$\mathrm{Oh}$ ! even further, they tried to bring all the imagination into real life. Then, a Trading Card Game established followed with the online version game. Fans now can play all explained in the comic and animation series and feel it in real life. They also can choose which one they like, A real trading card game or online Trading Card Game. Yet, all fans and all Card Game player in the world still believe that this game can be improved its gameplay in the future.

\section{B. Trends and today's game}

Technology is an issue to bring every aspect into next level. Some believe that. But authors believe the technology only a transportation to give a new era of game and give a new capability to its gameplay. The authors conducted some observations, we tried a lot of unique games and compare each other. From mobile phone, consoles, PC games, and augmented reality. One thing that made a game feels different is the experience from the users. Technology has showed us how we can interact with the digital world with the augmented reality. It is a bridge from one media to another. For example, with a comic we can tell more to the readers, if they download the application and shoot the comic in particular page, then they will see an animated version of the comic. It brings the comic itself to the next level. Even further it can be used as a promotional media to gain more readers. With an interactive comic the author is teasing the readers with the animated version of his/her comic, it shows a piece of story from the next episode, so the readers feel need to buy or grab the next episode of the comic.

The Trading Card Game also has its unique additional features. With the cards on the hand, user now can playing around to see their character in the card. By downloading the application, again the shoot the card then it will appear a 3D version of the character from the card. Imagine we have a card with a dragon illustration, we shoot the card using our smartphone. Today's smartphone has a very good quality of camera, combined with the application it will show us how beautiful the dragon is. We can see in $3 \mathrm{~d}$ space, zoom it, rotate it, use the camera as our eye. We can examine how the dragon is, the color, the shape, the details, also the ability of its character. The 3D hologram of the dragon also contained animations, it shows us its ability, for example the dragon can shoot a fireball from his mouth, or breath of fire just like a flamethrower placed inside the dragon's mouth.

Another example is we can use our phone and make it as a camera like the Samsung Gear, it attached in our head and covered all of our eyes with the phone screen. So we like wearing a goggle with the screen attached. This goggle brings another experience to the user, user will be placed in digital world all we can see is different world. By using this goggle and we walk around also turn our head around we are going to see the world also moving according where we walk or turn our head. This is give a feeling that we are inside the world and we can explore the world by walking around and seeing with our own eyes.

In addition, with technology a new era game can be developed. So many possibilities and the limit only the creativity. The Trading Card Game now using technology to have a different gameplay. The card only for preserve the character skills and abilities, the stronger card we have so we can beat the other player easily. This cards can only buy in several stores. The rare cards only sale in random store and random time. So it's like a treasure hunter. The Unique gameplay also bring this game into next level. Players have a new experience to play the game in different way. By using the card and their phone it shows the $3 \mathrm{~d}$ character on the card. A player then can put his card on the table and another player put his/her card on the table too. Two $3 \mathrm{~d}$ characters now standing on the cards. This can only be seen in their smartphone, with the particular application connected they can have a battle between two characters and fighting with its unique abilities. Therefore, the players control their character through their smartphones, the really fighting each other using their 3D characters with the table as an arena.

\section{Paruman The Khemion Master}

As authors already stated the problem we had in chemistry lesson that the students having problem to remember all the codes of chemistry. The authors found the students are easier to learn with fun. Thus, authors decided to make a game with a mission to give education or knowledge about chemistry 
periodic table in fun way. Students can play the game and try to remember all the codes in visual way with the creatures, monster or entity that represent every code itself. It proven in the game fields, all users can remember many characters since they love to play with that, love to digging up the characters. The key point in this state is how we can make the student love the characters which is about all of the chemistry codes.

Next, author find out how to trigger the student to love the chemistry code, an illustration or stunning visual can be a main attraction to the students [6]. So, authors developed some visual key represents the chemistry codes. Every unique code need to be break downed into several keywords. After the keywords chosen, it will continue to the visual phase. With a visual concept and all the keywords it guide the authors to deliver each character that represent the chemistry code.

With the stunning visual and unique gameplay that we adopted from the other card game, the authors believe it will give an opportunity to the students to learn chemistry using visual based periodic table. Also they will learn how to remember the codes using the gameplay that already designed to deliver the content easily. Khemion stands for Chemistry Monster, this term sounds interesting and unique also it represents 118 of total chemistry codes in periodic table. In this research, the authors created 20 characters out of 118 of chemistry periodic table.

\section{CONCLUSIONS}

Based on our research, we found out that a lot of students having dificulty with chemical lesson because of several reasons: a teacher that using traditional and monotone ways. Teacher should understand the way students think. Too many abstract phrase and minimum visual aid makes the lesson even more hard to understand for students. Therefore we create "Paruman The Khemion Master" to help students learn and memorized chemistry elements. Using a simple card game, we expect this method could be an altenate solution to help student learn chemistry. Our further development is having a "Paruman's" Mobile App and apply Augmented Reality technology on the card game.

\section{REFERENCES}

[1] Nurul Kamilati (2010). Kimia Sekolah Menengah Pertama

[2] Sutanto Windura (2009) Memory Champion! Rahasia Melejitkan Daya Ingat Super, Jakarta: PT. Gramedia

[3] Yudi Lesmana (2014). Memorizing Like An Elephant. Jakarta: PT. Gramedia

[4] Judy Willis (2010). Strategi Pembelajaran efektif berbasis riset otak, Jakarta

[5] Alexander Osterwalder \& Yves Pigneur (2010). Bisnis Model Generation, New jersey: john Wiley \& Sons, Inc.

[6] Sutanto Windura (2009) Memory Champion! Rahasia Melejitkan Daya Ingat Super, Jakarta: PT. Gramedia 